\title{
Casas de bambu, como uma solução de políticas públicas habitacional para região Amazônica
}

\author{
Bamboo houses, as a public housing policy solution for the Amazon Region
}

Nádia Caren dos Santos Arenas ${ }^{1}$, Marlene Valério dos Santos Arenas²*

\begin{abstract}
RESUMO
A busca por soluções criativas e de baixo custo que não impactem o meio ambiente e preservem os recursos naturais é a busca constante da arquitetura. A construção de casas populares utilizando o bambu podem ser uma dessas soluções. Esta pesquisa busca mapear por meio da literatura existente a viabilidade econômica de construção de casas populares com a utilização de bambu, como se processa a utilização do mesmo na construção civil, vantagens e desvantagens dessa utilização e por fim comparar a viabilidade econômica entre a construção de casas de alvenaria e de bambu. Trata-se de uma pesquisa exploratória, descritiva, qualitativa na busca de soluções criativas com a utilização do bambu. Os resultados demonstram que o bambu é viável economicamente, com reduzindo o custo e execução da obra em até 50\%, proporcionando uma construção flexível, criativa, adequada ao clima da região amazônica.
\end{abstract}

PALAVRAS-CHAVES: Bambu; Sustentabilidade; Construção.

\section{ABSTRACT}

The search for creative and low-cost solutions that do not impact the environment and preserve natural resources is the constant search for architecture. The construction of popular houses using bamboo can be one of these solutions. This research seeks to map, through the existing literature, the economic viability of building popular houses with the use of bamboo, how its use is processed in civil construction, advantages and disadvantages of this use and, finally, to compare the economic viability between the construction of brick and bamboo houses. It is an exploratory, descriptive, qualitative research in the search for creative solutions with the use of bamboo. The results demonstrate that bamboo is economically viable, reducing the cost and execution of the work by up to $50 \%$, providing a flexible, creative construction, suitable for the climate of the Amazon region.

KEYWORDS: Bamboo; Sustainability; Construction.

\section{INTRODUÇÃO}

Durante muito tempo julgou-se que a terra era um lugar de recursos infinitos, que a humanidade nunca teria preocupação em relação isso, e que o homem em suas ações não conseguiria afetá-la de forma incisiva ou irreparável. A partir da Revolução Industrial ficou claro que os processos produtivos geradores de riquezas, altamente poluentes, a

\footnotetext{
${ }^{1}$ Prefeitura Municipal de Porto Velho. E-mail:nadia.arenas@hotmail.com

${ }^{2}$ Fundação Universidade Federal de Rondônia. E-mail: marlenearenas @ unir.br*
} 
degradação ambiental inicia um percurso, que só pode ser freado com a participação efetiva e conscientização de toda sociedade (PINHEIRO, 2002)

A preocupação de como a ação humana impacta o meio ambiente fizeram com que diversos acordos internacionais fossem assinados, para que cada país faça sua parte, em prol da defesa e preservação do meio ambiente e dos recursos naturais, atingindo a sustentabilidade.

O Estado brasileiro assinou diversos acordos internacionais com esse objetivo, além de nos últimos anos ter alterado e/ou criado normas jurídicas com o intuito de tornar a ação humana menos impactante ao meio ambiente e aos recursos naturais.

É evidente que a construção civil causa grande impacto ao meio ambiente, afeta os recursos naturais de diversas formas e é altamente poluente. Pinheiro (2002) em sua pesquisa afirma que os resíduos resultantes das transformações produzidas na construção civil causam impacto ao meio ambiente, por meio dos resíduos sólidos e esses resíduos são responsáveis por emissões atmosféricas.

Por isso a preocupação com uma construção sustentável, já que o poder público tem entre suas ações, a obrigação de realização de políticas públicas de habitacional, em cumprimento ao que determina a Constituição Federal no que se refere aos direitos sociais, de que todos tem direito a moradia.

A arquitetura nos projetos de construção civil de casas populares tem por obrigação atentar-se aos acordos internacionais, a legislação vigente em nosso país, levando em conta o fator sustentabilidade, empregados nos materiais utilizados, exigir dos fornecedores materiais menos agressivos com custo benefício, verificar a certificação, garantias da procedência dos materiais, observando também o manejo sustentável e que a procedência desses materiais esteja dentro da legalidade.

Por meio de políticas públicas o poder público pode agir praticando um desenvolvimento sustentável, mobilizando os cidadãos na participação ativa e atuante da formulação dessas políticas públicas.

Esse mesmo poder público é responsável por diversas ações de sustentabilidade, e entre essas ações está em forçar as indústrias que são seus grandes fornecedores, já que é o maior comprador do país, a buscarem soluções menos agressivas ao meio ambiente.

Por ser o executor da política pública nacional de habitação, precisa buscar soluções criativas e implementar a construção de casas populares mais econômicas, confortáveis, observando a peculiaridade da região, com a utilização de recursos naturais abundantes no local, e ideais as condições climáticas. Se pergunta: "Qual a viabilidade econômica de construção de casas populares pelo governo utilizando bambu?"

Esta pesquisa tem como objetivo geral mapear por meio da literatura existente a viabilidade econômica da construção de casas populares com a utilização do bambu. E como objetivos específicos verificar na literatura existente como se processa a utilização do bambu na construção civil, quais as pesquisas existentes que relatam a utilização de 
bambu em construção de casas, quais as vantagens e desvantagens e comparar a viabilidade econômica entre a construção de casas de alvenaria e de bambu.

Este artigo foi elaborado a partir de um estudo exploratório, bibliográfico, com objetivo de identificar verificar na literatura existente a viabilidade econômica da construção de casas populares utilizando o bambu. Está dividido em quatro partes, iniciando por esta introdução, referencial teórico procedimentos metodológicos, análise dos dados e resultados e por último as considerações finais.

\section{CONTEXTUALIZANDO ARQUITETURA SUSTENTÁVEL}

\subsection{Acordos internacionais e legislação nacional sobre preservação do meio ambiente}

Diversas são as notícias em relação as mudanças climáticas, como enchentes que obrigam a população a deixarem suas casas, a crise hídrica sofrida pela população da região sudeste, níveis alarmantes de poluição nas grandes cidades, degradação da biodiversidade, que acabam por afetar os diferentes biomas, e demonstram a falta de cuidado com o meio ambiente.

A preocupação com o meio ambiente passou a ser um tema de grande relevância nos dias de hoje, em virtude da utilização dos recursos naturais de forma desmedida, sem que se preocupar com as consequências que impactam não só ao meio ambiente, como também a vida dos indivíduos.

Em nosso ordenamento jurídico há diversas leis relevantes que visam a proteção do meio ambiente. Inicialmente em nossa Constituição Federal de 1988 em seu art. 170, inciso VI, a defesa do meio ambiente, bem como a preocupação com o impacto ambiental dos produtos e serviços em todo o processo de elaboração e prestação, são uns dos princípios gerais da atividade econômica.

O texto legal do artigo 225 de nossa Carta Magna dispõe que o meio ambiente ecologicamente equilibrado é um direito de todos, por ser um bem de uso comum do povo e essencial à sadia qualidade de vida, impôs tanto ao Poder Público como à coletividade o dever de defender e preservá-lo, para a presente e futuras gerações.

Ao Poder Público cabe regulamentar o uso desses recursos ambientais, por meio da fiscalização, fomentar à pesquisa e fomentar o conhecimento acerca da área ambiental, e promover políticas públicas que incentivem a utilização de forma consciente do meio ambiente, além da educação continuada de mecanismos de defesa e preservação.

A preocupação com o meio ambiente não está disposta somente na Constituição Federal de 1988. Há outros dispositivos legais que devem ser obedecidos e demonstram essa preocupação, como a Lei 6.938/1981 em inciso I, do artigo $4^{\circ}$ que dispõe deverá existir compatibilidade entre o desenvolvimento econômico e social com a preservação ambiental. 
Essa preocupação está clara também em diversas leis, como no inciso VIII, do art. $2^{\circ}$ da Lei 10.257/2001 que dispõe a adoção de padrões de produção e consumo de bens e serviços [...] compatíveis com os limites da sustentabilidade ambiental [...]. A Lei 12.187/2009, art. $4^{\circ}$, I, art. $6^{\circ}$, XII, prevê a necessidade de compatibilizar o desenvolvimento econômico-social com a proteção do sistema climático.

A adoção de medidas de defesa e proteção ao meio ambiente não está somente previsto na nossa Constituição federal e legislação federal, mas também advêm de compromissos internacionais assumidos pelo Estado Brasileiro em prol do desenvolvimento e consumo sustentáveis.

Os direitos humanos fundamentais centrado na pessoa humana, é inalienável está previsto na Declaração sobre o Direito ao Desenvolvimento, conforme Resolução n. 41/128 da Assembleia Geral das Nações Unidas em 04 de dezembro de 1986. Direito ao desenvolvimento, ao meio ambiente sadio e desenvolvimento sustentável são universais, indivisíveis, interdependentes de acordo com a Conferência Mundial sobre os Direitos do Homem (Declaração de Viena, 1993). Declaração de Estocolmo 1972, Declaração da Conferência das Nações Unidas sobre o Meio Ambiente Humano. Protocolo de San Salvador ratificado pelo Brasil em 21 de agosto de 1996.

Declaração do Rio sobre Meio Ambiente e Desenvolvimento em 1992 que afirma em seu principio 8 que "para alcançar o desenvolvimento sustentável e uma qualidade de vida mais elevada para todos, os Estados devem reduzir e eliminar os padrões insustentáveis de produção e consumo [...]". Agenda 21 que segue o princípio de "pensar globalmente, agir localmente"

Essa preocupação se estendeu às compras de bens e serviços realizadas pelo Poder Público, com a alteração do artigo $3^{\circ}$ da Lei 8.666/1993. Preocupação essa demonstrada com a inclusão de que as aquisições realizadas devem observar "a promoção do desenvolvimento nacional sustentável", além da observância ao princípio constitucional da isonomia, seleção da proposta mais vantajosa. Segundo Justen Filho (2010) esses objetivos devem nortear o processo licitatório, pois indicam os princípios jurídicos mais relevantes que subordinam as aquisições realizadas pelo Poder Público, chamadas de licitações sustentáveis.

A regulamentação desse artigo veio por meio do Decreto 7.746 de 05 de junho de 2012, onde foram estabelecidos critérios, práticas e diretrizes de sustentabilidade relevantes, tanto para esfera social como para a ambiental, no que tange a promoção do desenvolvimento nacional sustentável nas contratações realizadas pela administração pública federal. Entre essas diretrizes estão a de menor impacto sobre os recursos naturais como flora, fauna, ar, solo e água; preferência para materiais, tecnologias e matériasprimas de origem local; maior eficiência na utilização de recursos naturais como água e energia; maior geração de empregos, preferencialmente com mão de obra local; maior vida útil e menor custo de manutenção do bem e da obra; uso de inovações que reduzam 
a pressão sobre recursos naturais; e origem ambientalmente regular dos recursos naturais utilizados nos bens, serviços e obras.

O decreto ainda prevê que os editais e/ou instrumentos convocatórios poderão dispor que o contratado adote práticas de sustentabilidade na execução dos serviços contratados, bem como critérios de sustentabilidade quando for o caso de fornecimento de bens.

A Lei 12.187/2009, art. $6^{\circ}$, XII, que trata da política nacional de mudança climática, dispõe sobre o estabelecimento de critérios de preferência nas licitações [...] para as propostas que propiciem maior economia de energia, água e outros recursos naturais e redução da emissão de gases de efeito estufa e de resíduos.

O Poder Público como grande comprador que é passa a ter um papel de grande importância no cumprimento desses acordos internacionais, assim como cumprimento da Constituição brasileira e legislações vigentes. Essa obrigação reflete também na realização de políticas públicas relacionadas a construção de casas populares, que é o foco deste artigo.

\subsection{Políticas públicas de habitação}

O direito a moradia é um dos direitos sociais previstos em nossa Constituição Federal de 1988, em seu artigo $6^{\circ}$. Embora o Brasil tenha adotado ao longo dos anos diversas políticas públicas relacionadas a habitação para a população de baixa renda, esse caminho foi marcado por diversas mudanças na concepção e modelo de intervenção adotados pelo poder público, que até o presente momento sem sucesso.

Com a Constituição de 1988 ocorreu um processo de descentralização políticoadministrativa do país previsto no art. 182, que redefiniu competências passando as atribuições da gestão de programas sociais e de habitação para os Estados e Municípios.

Esse processo de mudança ao longo dos anos passou por mudanças importantes como a criação dos Sistema Financeiro de Habitação (SFH), considerado um marco fundamental da intervenção do poder público no setor de habitacional, diante da carência habitacional existente na população de baixa renda. Esse sistema atendeu também a população de média e alta renda.

O SFH fracassou devido a grande inadimplência e com isso foram criados programas habitacionais destinados especificamente a população de renda inferior a três salários mínimos. Assim como diversos outros que também fracassaram, e o déficit habitacional só aumentou ao longo dos anos, enquanto os recursos públicos se tornaram cada vez mais escassos para esse fim social.

Com a implantação do Programa de Aceleração do Crescimento (PAC), que surgiu em março de 2009, o Programa Minha Casa Minha Vida (PMCMV), que está integrado ao Plano Nacional de Habitação (PlanHab). É um programa do governo federal, cuja operacionalização compete a Caixa Econômica Federal, que utiliza os recursos do 
Fundo de Arrendamento Residencial (FAR). Esses recursos são geridos pelo Ministério das Cidades, cuja população alvo são as famílias com renda bruta até R \$ 4.900,00 (quatro mil e novecentos reais).

Diante desse cenário, vem a preocupação com soluções criativas, baseada em uma arquitetura sustentável, para atender essa necessidade da população de baixa renda, com a construção de casas populares viavelmente econômicas, aliadas as condições peculiares da região amazônica.

\subsection{Arquitetura sustentável}

O país e o mundo têm passado por diversas transformações a partir do processo de industrialização advindo após a Segunda Guerra Mundial, que acabaram por provocar $\mathrm{o}$ esgotamento de muitos recursos naturais. $\mathrm{O}$ que acarretou preocupações com o meio ambiente e respeito ao mesmo.

A arquitetura não pode ficar indiferente a todos esses problemas ocorridos com o mau uso dos recursos naturais e agressão ao meio ambiente. Passou-se a busca constante por soluções criativas, ecologicamente corretas, que aliem conforto, sem agredir o meio ambiente, não poluentes e sem esgotar recursos naturais. Também chamada por muitos de "arquitetura sustentável", "arquitetura ecológica" ou "arquitetura verde".

Para Souza (2004) "o conceito da arquitetura ecológica é simples: a habitação deve ser construída com materiais naturais renováveis e, acima de tudo, não poluentes". Afirma ainda que os diversos arquitetos passaram a projetar moradias que aliam conforto e respeito à natureza. Exemplos disso são soluções criativas, como grama sobre o teto, parede de terra crua, bambu, madeira de reflorestamento e tijolos que respiram, colocamse como novas opções dentro da gama de materiais usualmente utilizados pelo mercado da construção convencional.

\section{Ainda Souza (2004, p.228);}

As técnicas tradicionais de construção, algumas milenares, como a utilização de terra crua, bambu e fibras vegetais representam uma excelente alternativa aos materiais industrializados. Não são poluentes, não requerem grande consumo de energia e oxigênio em seu processo de preparo, são renováveis e de baixo custo, não deixando de lado a beleza estética.

A edificação em si deve ser projetada de forma que interaja com o meio em que se insere, pois o entorno é o começo de tudo. Portanto, respeitar a topografia e vegetação existente, desenvolver estudo de impacto ambiental, analisar a adequação a planos urbanísticos e verificar a infraestrutura existente (água, energia, transportes, coleta de lixo) é fundamental. Além disso, o projeto deve ser concebido utilizando sempre iluminação e ventilação naturais, com orientação da edificação bem planejada, assim como suas formas, com atenção para o uso correto de proteções solares e a especificação dos materiais, entre outros vários aspectos. Deve-se tirar o máximo proveito das 
condições climáticas da região para se obter maiores contribuições no uso eficiente e na racionalização da energia, sem esquecer de garantir o conforto dos usuários. A eficiência energética nas edificações pode ser entendida como um baixo consumo de energia proporcionando as mesmas condições ambientais e segundo a PROCEL a redução do consumo de energia é essencial, as economias podem chegar a $30 \%$ em edificações existentes e 50\% nas projetadas dentro dos conceitos de eficiência energética (VILELA, 2007).

Ainda Vilela (2007) afirma que os materiais construtivos e tecnologias empregadas, favorecem mais ou menos o bom aproveitamento dos recursos naturais e contribuem para a redução do consumo energético na edificação. Importante a seleção de materiais que tenham um menor impacto possível sobre o meio ambiente a utilização de materiais procedentes de fontes renováveis ou reciclados. Para tanto, é necessário conhecer o ciclo de vida de um material em todas as suas fases, desde os impactos provocados pela extração da matéria-prima, passando pelo transporte, aplicação final, desempenho, longevidade do material, capacidade de reutilização, reciclagem até a sua decomposição. Essencial é verificar a toxidade do material para o homem e para o meio ambiente, por isso a importância de normas e selos de qualidade dos materiais e equipamentos empregados na construção.

\subsection{Utilização do bambu na construção civil}

A arquitetura ao longo desses últimos anos, tem buscado diversas soluções como falado anteriormente, e entre uma das soluções criativas está a utilização do bambu como matéria-prima na utilização de construção de casas ecologicamente sustentáveis.

Essa utilização foi base de estudos de análises comparativas entre o bambu e a madeira utilizada de reflorestamento, conforme Morado (1994) que afirma que o bambu é uma planta, auto renovável, de crescimento rápido, fácil plantio, podendo crescer até 25 $\mathrm{cm}$ por dia. Algumas espécies completam seu crescimento em 40 dias, mas apenas após 3 anos se inicia seu processo de lignificação e silificação. Além de sua resistência natural, possui boa resistência ao tempo, quando recebe o tratamento adequado para sua utilização, é tão eficaz quanto a madeira, podendo a substituir parcialmente e futuramente até completamente. Enquanto a madeira de reflorestamento após o seu plantio demora cerca de 60 anos para atingir $18 \mathrm{~m}$ e chegar a fase adulta para se tornar apta ao corte.

Quanto ao aspecto de resistência Souza (2004) afirma que o bambu possui os colmos na maioria ocos, composto de fibras que na forma como são distribuídas são mais densas na parte externa, chegando a centímetros, compondo um misto de lignina e silício. Esses dois elementos agregam resistência mecânica (silício) ao bambu e a matriz de lignina dá flexibilidade. O bambu tem alta resistência ao longo do colmo e baixa resistência no sentido transversal às fibras. As folhas são usadas em paredes e coberturas 
por serem um bom isolante. Tem baixo peso específico, alta resistência à tração, baixo custo e fácil manejo, dispensando mão-de-obra especializada no seu manuseio.

O bambu possui características mecânicas ${ }^{3}$ no que se refere 1) compressão - peças curtas de bambu podem suportar tensões superiores a $50 \mathrm{MPa}$, superando a resistência dos concretos convencionais. Além disso, o concreto tem densidade superior a 2 e o bambu apresenta 1/3 desse valor. Desse modo, se for considerada a resistência em relação à densidade (resistência específica), o bambu mostra-se mais eficiente do que o concreto; 2) Tração paralela às fibras - O módulo de elasticidade do bambu situa-se em torno de 20.000 MPa, cerca de 1/10 do valor alcançado pelo aço. Cabos de bambus trançados oferecem resistência similar ao aço CA-25 (2.500 kgf/cm2). O peso, no entanto, é $90 \%$ menor e 3) Flexão estática - o bambu apresenta rigidez suficiente para que possa ser utilizado em estruturas secundárias, na forma de treliças e vigas. Na Colômbia, Equador e Costa Rica foram desenvolvidos importantes projetos estruturais com o Guadua Angustifolia.

A Tabela 1 abaixo demonstra a resistência mecânica de duas espécies de bambu in natura que são recomendadas para utilização em construção civil

Tabela 1 - Resistência Mecânica das espécies de bambu - construção civil

\begin{tabular}{l}
\hline $\begin{array}{l}\text { RESISTÊNCIA MECÂNICA DAS ESPÉCIES RECOMENDADA PARA CONSTRUÇÃO } \\
\text { CIVIL }\end{array}$ \\
\begin{tabular}{l|l|l|l|l} 
Espécie & $\begin{array}{l}\text { Tração } \\
(\mathrm{MPa})\end{array}$ & $\begin{array}{l}\text { Compreensão } \\
(\mathrm{MPa})\end{array}$ & $\begin{array}{l}\text { Flexão } \\
(\mathrm{MPa})\end{array}$ & $\begin{array}{l}\text { Cisalhamento } \\
(\mathrm{MPa})\end{array}$ \\
\hline $\begin{array}{l}\text { Dendrocalamus.Giganteus (bambu } \\
\text { gigante) }\end{array}$ & 135 & 40 & 108 & 46 \\
\hline \begin{tabular}{l} 
Guadua Superba (Taquaruçu) \\
\hline
\end{tabular} & 130 & 42 & 102 & 48 \\
\hline
\end{tabular}
\end{tabular}

Fonte: Adaptado de Marcos Tadeu Tibúrcio Gonçaves, Unesp Bauru

Na Tabela 2 abaixo demonstra a resistência mecânica de bambu na forma laminado

Tabela 2 - Resistência Mecânica de bambu laminado colado e serrado

\begin{tabular}{l|c}
\hline RESISTÊNCIA MECÂNICA DE AMOSTRAS DE BAMBU LAMINADO COLADO E \\
SERRADO & Resistência (MPa) \\
\hline Ensaio & 35 \\
\hline Bambu laminado colado & 55 \\
\hline Dureza & 18 \\
Compressão paralela às fibras & 195 \\
Compressão normal às fibras & 2,5 \\
\hline Tração paralela às fibras & \\
\hline Tração normal às fibras & \\
\hline
\end{tabular}

3 Construções de bambu | Téchne. Disponível em <http://techne.pini.com.br/engenhariacivil/108/artigo2860551.aspx>. acesso em 09 dez 2015 


\begin{tabular}{l|c}
\hline RESISTENCIA MECÂNICA DE AMOSTRAS DE BAMBU LAMINADO COLADO E \\
SERRADO & Resistência (MPa) \\
\hline Ensaio & 10 \\
Cisalhamento & 166 \\
Flexão & 89 \\
Bambu laminado - ripa & 161 \\
\hline Compressão paralela às fibras (amostra reduzida da norma) & 298 \\
Tração paralela às fibras & 137 kJ/m² \\
Flexão (amostra reduzida da norma) & \\
Resistência ao impacto na flexão - Tenacidade & \\
\hline
\end{tabular}

Fonte: Marcos Tadeu Tibúrcio Gonçalves, Unesp Bauru ${ }^{4}$

O bambu tem sua utilização nas construções civis bastante abrangente, em virtude do seu baixo custo e tendo outro fator relevante em relação ao seu elevado comprimento que possibilita estruturas espaçosas e com grandes pés-direitos. Pode ser utilizado também, nas paredes substituindo tijolos por painéis de vedação, assim como nas vigas, esqueleto das estruturas, coberturas, tendas, armadura de elementos estruturais de concreto armado, formas, escoramentos de lajes, arcos, cúpulas, corrimão, mobiliários, pisos laminados, adornos, utensílios domésticos. Morado (1994) afirma que se deve ter um olhar atento ao bambu que pode revelar soluções novas, que incorporem tecnologia, como é o caso das juntas estruturais desenvolvidas no Joint Research Programam on Natural Structures.

Há que se observar algumas técnicas quanto a colheita, tratamento e armazenamento que envolve a utilização, qualidade e principalmente durabilidade do uso do bambu na construção civil, segundo Beraldo (2006) $)^{5}$ :

O bambu apresenta baixa durabilidade natural por causa da presença do amido, que atrai fungos. Para prolongar a vida útil do bambu, existem algumas técnicas, como observação da idade para o corte, porque os colmos maduros (com mais de três anos) geralmente são mais resistentes aos ataques de fungos e de insetos, além de apresentarem melhor desempenho mecânico. O maior problema refere se ao desconhecimento da idade dos colmos, já que a marcação anual, na maioria das vezes, não é feita regularmente.

Muitas vezes a cura é feita na mata, quando os colmos de bambu são cortados e deixados para secar na própria touceira, geralmente apoiando-se a base inferior do colmo em uma pedra. Quando as folhas secam e caem, o colmo já pode ser utilizado. Essa técnica, facilita a degradação do amido e da seiva presentes no colmo, aumentando a durabilidade.

4 Construções de bambu | Téchne. Disponível em <http://techne.pini.com.br/engenhariacivil/108/artigo2860551.aspx>. acesso em 09 dez 2015

5 Antonio Ludovico Beraldo, da Unicamp, REVISTA TÉCHNE- Construções de bambu Reportagem de Giuliana Capello. 2006. Disponível em <http://techne.pini.com.br/engenhariacivil/108/artigo286055-1.aspx>, acesso em $11 \mathrm{dez} 2015$. 
Outra técnica de tratamento é por imersão, quando os colmos podem ser imersos em água (parada ou corrente), ou em soluções preservativas. Em alguns casos os colmos devem ser recém cortados. Em outros, pode-se utilizar colmos secos ao ar. Quando feito por aspersão, apresenta pouca eficiência, já que a absorção do produto é feita apenas pelas extremidades do colmo.

Há também o tratamento pela fumaça e pelo fogo: os colmos recém cortados são colocados em fogo rápido. Também se pode desenvolver um tipo de defumador que, em bambus alastrantes, provoca o escurecimento dos colmos, tornando-os muito atraentes para fins ornamentais. Aparentemente, o efeito do calor e da fumaça alteram ou degradam o amido, tornando o colmo mais resistente ao ataque do caruncho. Para aplicações em escala comercial devem ser projetadas instalações específicas para esse fim (de preferência com recuperação dos produtos químicos eliminados).

$\mathrm{O}$ tratamento sob pressão torna o processo mais eficiente. O método mais recomendado para colmos recém-cortados é o Boucherie modificado. Bambus secos podem ser tratados em autoclaves (utilizadas para preservação da madeira). Nesse caso, os diafragmas devem ser perfurados para que o colmo não rache durante a fase de vácuo. É necessário também fazer um tratamento preventivo para que, durante a secagem, os colmos não sejam atacados pelo caruncho.

A colheita e armazenamento do bambu devem ser realizados da forma correta para melhor aproveitamento. A colheita deve ser realizada durante a temporada seca para que os troncos do bambu tenham um baixo conteúdo de umidade, o que facilita seu transporte e diminui a possibilidade de um ataque de fungos e de apodrecimento. Devem ser coletados apenas os troncos adultos porque os jovens fornecem alimento ao bambu. É importante que não se corte muitos troncos da mesma planta, pois isso causa um dano irreparável

que, a longo prazo, pode causar a morte da planta. O mesmo cuidado deve ser observado, pois o armazenado sob uma cobertura para se proteger da chuva e, de preferência sem encostar no solo. O solo deve estar limpo, sem lixo e livre de cupins, com boa ventilação. Se o bambu fresco for armazenado em posição vertical estará seco em quatro semanas, e se estiver armazenado horizontalmente, demorará o dobro para secar. Se o bambu secar rápido demais, pode rachar ${ }^{6}$.

Como já foi observado acima a utilização do bambu, tem diversas vantagens sendo as principais flexibilidade, resistência e beleza. Após pesquisas feita com a matéria-prima, vale ressaltar alguns cuidados básicos que se deve ter ao utilizá-lo na construção, após a escolha da espécie ideal do bambu e seu devido tratamento.

\footnotetext{
${ }^{6}$ Bambu - Prós e contras. Disponível em <http://www.recriarcomvoce.com.br/blog_recriar/bambuprscontras/>, acesso em $07 \mathrm{dez} 2015$.
} 
Para Souza (2004, pg. 237);

O que garante a estabilidade da estrutura são os encaixes. Os encaixes são as ligações de peças de bambu, que podem ser feitas do próprio bambu, de metal, madeira, cordas, parafusos, arames etc. Deve ser cuidadosamente executada devido à necessidade de executar furos. O uso de parafuso de ferro com arruela e porca é o mais indicado para os nós estruturais primários. Já nos nós ou apoios secundários pode ser usado amarra com arame galvanizado ou corda.

Nas ligações estruturais devemos evitar o contato entre as peças de bambu e bambu com o parafuso, para não acontecerem fissuras ou esmagamento. Então, deve-se usar borracha ou silicone, que permite melhor ajuste entre as peças. É recomendado o enrijecimento do interior dos colmos nos pontos mais solicitados com a injeção de resina, concreto ou madeira. O uso da amarra deve estar associado a pinos ou parafusos, tendo assim maior estabilidade.

Há uma diferença entre a arquitetura que se preocupa com a fonte dos materiais de construção, seus processos de fabricação, transporte, destinação, reuso dos produtos, buscando a máxima autossuficiência de energia e água, que se traduz em construir com um mínimo de impacto ao meio ambiente e a arquitetura bioclimática, influenciada pelo clima (VILELA, 2007 e PINHEIRO, 2002).

\subsection{O clima e o bambu}

Segundo Lamberts, Dutra e Pereira (1997) a temperatura, a umidade, a radiação solar e ação do vento, são fatores dinâmicos que mais influenciam o conforto térmico das edificações.

É crescente os projetos arquitetônicos que integram natureza e clima. Chamada por alguns arquitetos de arquitetura bioclimática (OLIVEIRA, 2006). Na realidade é uma arquitetura pensada em relação ao ambiente local, principalmente em relação ao seu clima (OLIVEIRA, 2006; CALDAS, 2002). É uma adaptação da produção arquitetônica às condições climáticas locais, buscando conjunto de recursos teóricos que dêem subsídios para um planejamento da edificação aproveitando os elementos do clima para satisfazer exigências de conforto térmico, utilizando estratégias de projetação para vencer as adversidades climáticas (OLIVEIRA, 2006; CALDAS, 2002).

A arquitetura bioclimática e o eco desenho tem como objetivo trazer para edificação condições naturais oferecidas pelo seu entorno, ecologicamente eficiente, tirando a maior qualidade de conforto térmico dos elementos climáticos da região, influenciando diretamente no consumo energético da habitação (OLIVEIRA, 2006).

De acordo com Lima (2010) as habitações consideradas sustentáveis precisam estar pautadas no bem estar do homem, de seu meio, no sistema construtivo, preservando e respeitando as condicionantes regionais: paisagem, clima e os recursos que essa região lhe oferece e os materiais usados necessitam estar assegurados para as gerações presentes e futuras. 


\section{PROCEDIMENTOS METODOLÓGICOS}

A presente pesquisa está classificada como qualitativa, exploratória, quanto aos objetivos, este tipo de pesquisa possibilita maior proximidade com o fenômeno estudado, por meio de planejamento flexível que permita uma visão geral da situação ou fenômeno, geralmente envolve pesquisa de natureza qualitativa.

A pesquisa busca gerar conhecimentos novos e úteis acerca de construção de casas de bambu, visando o avanço da ciência nesse ramo. O estudo descritivo que observa, registra e analisa as informações obtida, iniciou com a contextualização sobre os acordos internacionais e a legislação vigente, arquitetura sustentável, bambu, construções de casas com bambu e o clima para melhor descrever o estudo.

Segundo Oliveira (2011), método pode ser definido pelo pesquisador como o caminho escolhido para a pesquisa sobre o tema abordado, buscando solucionar ou aclarar os problemas encontrados, atingindo os objetivos propostos por meio de procedimentos pré-definidos.

Trata-se de uma pesquisa bibliográfica porque se vale de matérias e métodos já existentes e elaborados por outros autores, elaborada a partir de conteúdos publicados sobre o tema abordado, por meio de livros, revistas, publicações em periódicos, artigos científicos, web, monografias, dissertações, teses, entre outros.

\section{RESULTADOS E DISCUSSÃO DOS DADOS}

O estudo exploratório da literatura existente sobre a utilização do bambu na construção de casas, demonstra que a técnica construtiva apesar de ser pouco utilizada no Brasil, já foi adotada a séculos em mega construções por países como Japão e China, que se expandiram ao Peru, Equador e Colômbia. Inclusive a Colômbia adotou a técnica em casas de habitações populares.

$\mathrm{O}$ que se verificou na literatura que o processo de utilização do bambu em construção de casas, é possível, devido ao fato de ser uma planta de alta resistência, flexibilidade e durabilidade, que pode ser usada tanto na estrutura como em adornos, ou seja, de um extremo ao outro, e tem várias utilidades em uma construção.

A Figura 1, a seguir, demonstra como o bambu pode ser utilizado de diversas formas na construção de casas, na estrutura, desde o pé direito até a beleza e criatividade nas fachadas. 
Figura 1 - Fachada, mezzanino, pé direito

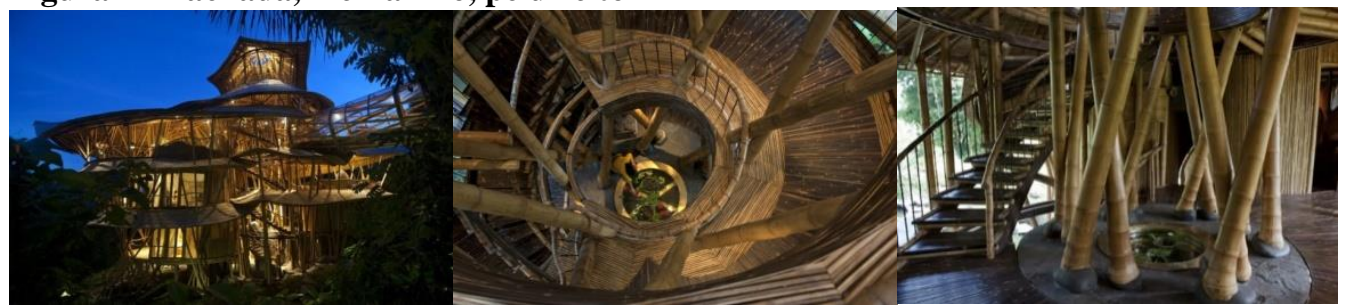

Fonte: http://www.hypeness.com.br/2014/09/

baliabrigaenormecasasustentavelfeitadebambuondevocepodesehospedar/

A Figura 2, a seguir, demonstra claramente a versatilidade sem limite para criatividade que o bambu possui inclusive a sua utilização em adornos para habitação.

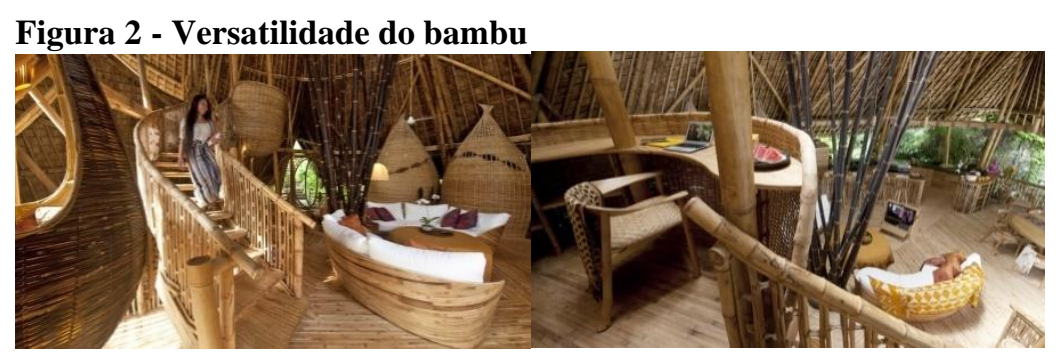

Fonte: http://atitudesustentavel.com.br/blog/2013/08/20/

conhecaascasasdebambudaindonesia/

A literatura demonstra que é uma planta auto renovável, o que caracteriza a sua importância perante a preservação e defesa dos recursos naturais. Para tanto, há necessidade da utilização consciente e correta, por ser uma planta que não precisa do replantio, se o corte ocorrer após três anos, pois o broto é que fornece a seiva para alimentação do bambu, até que chegue a fase apta para corte. O corte a partir dessa idade, é o melhor momento, pois o bambu é duro como madeira.

O Norte do Brasil, conhecido também como região Amazônica, tem como clima predominante tropical úmido, que é quente, chuvoso, com muitas vegetações e temperaturas semelhantes durante o dia e noite.

É na região Norte do Brasil, onde ocorre a maior produção de bambu, e o maior produtor é o Estado do Acre, que atinge cerca de 38\% do plantio de diversas espécies. Isso ocorre por ser uma região quente e úmida, propícia para esse tipo de vegetação.

Em relação ao clima da região amazônica é importante citar alguns aspectos construtivos importantes na hora da execução do projeto, como: janelas grandes, corredores ao redor da habitação proporcionando corrente de ventos em seu entorno, varandas e beirais grandes, fachadas principal norte, paredes estreitas evitando conservação da umidade, na cobertura utilizar materiais com conforto térmico satisfatório, ventilação cruzada considerando os ventos predominantes da região, localização dos dormitórios priorizando fachada leste (sol da manhã), pé-direto alto, 
utilização de materiais térmicos, como: madeira, barro, bambu, capim, etc., corroborando com a pesquisa de Souza (2004).

As pesquisas existentes que relatam a utilização de bambu em construção de casas apresentam vantagens e desvantagens, em relação a sua utilização.

Quadro 1- Vantagens e desvantagens da utilização do bambu

\begin{tabular}{|c|c|}
\hline VANTAGENS & DESVANTAGENS \\
\hline Abundância que leva ao baixo custo e economia & Quando muito seco pode pegar fogo \\
\hline Não poluente & $\begin{array}{l}\text { Apodrece se ficar em constante contato com } \\
\text { umidade }\end{array}$ \\
\hline Baixo impacto ambiental & $\begin{array}{l}\text { Está propenso ao ataque de insetos e cupim, quando } \\
\text { não tratado adequadamente }\end{array}$ \\
\hline Beleza estética & Não tem uma perfeita linearidade ou padronização \\
\hline Ecológico & $\begin{array}{l}\text { Tem tendência a rachar, fissurar e esmagar, } \\
\text { dependendo do método construtivo }\end{array}$ \\
\hline Prático, podendo ser associado a outros materiais & Pode contrair-se quando usado no concreto armado \\
\hline Crescimento rápido & $\begin{array}{l}\text { A parte interna é mais concentrada em amido e é } \\
\text { menos resistente. }\end{array}$ \\
\hline Não precisa ser replantado após o corte, auto - renovável & $\begin{array}{l}\text { O bambu está sujeito a variações dimensionais } \\
\text { causadas pela absorção da umidade }\end{array}$ \\
\hline Produz mais ou menos 20 toneladas por hectare & $\begin{array}{l}\text { Há variações de acordo com a espécie, plantio, } \\
\text { corte, cura, secagem e estocagem }\end{array}$ \\
\hline Leve (devido ao baixo peso específico e seção circular oca) & $\begin{array}{l}\text { Mais resistente à tração do que à compressão devido } \\
\text { ao sentido longitudinal das fibras }\end{array}$ \\
\hline Fácil transporte e armazenamento & $\begin{array}{l}\text { A durabilidade, rendimento estrutural e eficiência } \\
\text { dependem diretamente da secagem e dos } \\
\text { tratamentos aplicados }\end{array}$ \\
\hline Boa resistência e flexibilidade & A maior desvantagem é a falta de padronização \\
\hline \multicolumn{2}{|l|}{$\begin{array}{l}\text { A própria planta (o bambuzal) ajuda na contenção do } \\
\text { terreno em casos de erosão e até mesmo em terremotos }\end{array}$} \\
\hline \multicolumn{2}{|l|}{$\begin{array}{l}\text { A parte externa do colmo é mais resistente devido à } \\
\text { concentração de lignina, substância aglutinante }\end{array}$} \\
\hline \multicolumn{2}{|l|}{$\begin{array}{l}\text { O diafragma (nó) aumenta a resistência da cana contra } \\
\text { flexão e ruptura }\end{array}$} \\
\hline \multicolumn{2}{|l|}{ É um bom isolante acústico e térmico } \\
\hline Tem aparência de material acabado & \\
\hline
\end{tabular}

Fonte: adaptado de Souza (2004)

Quanto ao apodrecimento, ataque de insetos, cupins e o amido existente na parte interna, apresentado como desvantagem, Beraldo (2006) demonstrou que pode ser evitado com o tratamento adequado. Portanto, só poderia ser considerado desvantagens, senão observado o correto tratamento. A eficiência do tratamento está diretamente ligada a durabilidade, rendimento estrutural. 
Assim como a tendência a rachadura, fissura e esmagamento, Souza (2004) demonstra que se utilizar o método construtivo adequado, isso não ocorre, pois deve-se proceder por meio do uso de parafuso de ferro com arruela e porca, que é o mais indicado para os nós estruturais, já que nos apoios secundários pode ser usado amarra com arame galvanizado ou corda, lembrando que o bambu possui resistência a tração.

No Paraná a ligação está sendo feita por garrafas pet, aquecidas a um vapor na temperatura de $400^{\circ}$ graus, fixando um bambu ao outro, criando painéis de vedação para substituição de tijolos.

Pela versatilidade do uso do bambu, a falta de linearidade e padronização não se torna uma desvantagem.

A possibilidade de quando seco pegar fogo, na literatura Souza (2004) afirma que o bambu se torna mais resistente ao fogo quando aplicado na vertical do que na horizontal, devido ao teor de sílica, sua grande densidade e ao sentido das fibras.

Por fim, a viabilidade econômica entre a construção de casas de alvenaria e de bambu fica clara, pois a cada dia o bambu está conquistando seu lugar no Brasil, diferente do que vemos pelo mundo em países como a China, Japão, Equador, Peru e Colômbia, onde o bambu já conquistou seu espaço no meio da construção civil.

Uma casa popular de alvenaria custa em média $\mathrm{R} \$ 40.000,00$ (quarenta mil reais), se comparando a construção de uma casa utilizando bambu, esse custo reduz em aproximadamente $50 \%$ e ganha agilidade no tempo de execução em até $50 \%$ também, se utilizar $70 \%$ da matéria-prima sugerida.

Uma das grandes resistências na utilização do bambu no Brasil, se dá por ser um país que foi colonizado por europeus, que trouxeram na sua cultura a construção de casas em alvenaria, o que não é viável para a região amazônica, por não trazer conforto térmico.

Outro ponto importante é que o Brasil, principalmente na região amazônica, temos o Estado do Acre como maior produtor dessa matéria-prima (bambu) e de diversas espécies, o que seria uma solução viável e ecologicamente correta de preservação, defesa dos recursos naturais e meio ambiente, trazendo conforto e menor poluição.

A literatura desmistifica de que a utilização do bambu, somente ocorria em casas de construções precárias, de pau-a-pique, com barro, de pessoas pobres, por isso sua utilização foi abandonada à épocas, deixando seu uso uma opção sem prestígio.

A literatura demonstra que é viável a utilização do bambu em projetos de casas populares pelo poder público, principalmente se analisarmos sua utilização ao longo dos anos, e a renovação rápida dos recursos naturais (bambu) utilizado, por ser auto renovável até de três anos.

Há que observar que aliado a utilização do bambu na construção, não se pode esquecer que devem estar imbricados no projeto o respeito a topografia, vegetação, devendo ser concebido utilizando sempre iluminação e ventilação naturais, tirando 
proveito ao máximo das condições climáticas da região, corroborando o exposto por Vilela (2007).

\section{REFERÊNCIAS}

BRASIL. Política Nacional do Meio Ambiente. Lei n ${ }^{\circ}$ 6.938, de 31 de agosto de 1981. Disponível em: <http://www.planalto.gov.br/ccivil_03/leis/16938.htm>. Acesso em: 08 set 2015

BRASIL. Constituição da República Federativa de 1988. Disponível em: <http://www.planalto.gov.br/ccivil_03/constituicao/constituicaocompilado.htm >. Acesso em 15 set 2015

BRASIL. Normas para licitações e contratos na Administração Pública. Lei n ${ }^{\circ}$ 8.666, de 21 de junho de 1993. Disponível em: <http://www.planalto.gov.br/ccivil_03/Leis/L8666cons.htm>. Acesso em 16 set 2015.

BRASIL. Política Nacional de Resíduos Sólidos. Lei n 12.305, de 02 de agosto de 2010. Disponível em: < http://www.planalto.gov.br/ccivil_03/_ato20072010/2010/lei/112305.htm>. Acesso em 30 set 2015.

BRASIL. Política Nacional sobre Mudança do Clima - PNMC. Lei n ${ }^{\circ}$. 12.187, de 29 de dezembro de 2009. Disponível em: <http://www.planalto.gov.br/ccivil_03/_ato20072010/2009/lei/l12187.htm> Acesso em 20 set 2015

BRASIL. Regulamenta o art. $3^{\circ}$ da Lei $n^{\circ} 8.666$, de 21 de junho de 1993. Decreto $n^{\circ}$ 7.746, de 05 de junho 2012. Disponível em: <http://www.planalto.gov.br/ccivil_03/_ato2011-2014/2012/decreto/d7746.htm> Acesso em 12 out 2015.

JUSTEN FILHO, Marçal. Comentários à Lei de licitações e contratos administrativos. 14 ed. São Paulo: Dialética, 2010.

LAMBERTS, Roberto; DUTRA, Luciano; PEREIRA, Fernando Oscar Ruttkay. Eficiência energética na arquitetura. São Paulo: PW, 1997.

LIMA, Valdeci Candido de. A sustentabilidade da Habitação do seringueiro amazônico. Pós v. 17 n. 28. São Paulo. dezembro 2010. p. 181-197. Disponível em < www.revistas.usp.br/posfau/article/download/43707/47329>. Acesso em 09 nov 2015 
MORADO, Denise. Material de Fibra. Revista téchne, São Paulo, n.9, p.32-36, mar/abr. 1994.

OLIVEIRA, Thaisa Francis C. Sampaio de. Sustentabilidade e arquitetura: uma reflexão sobre o uso de bambu na construção civil. 2006. 136f. Dissertação (Mestrado em Dinâmicas do Espaço Habitado) - Centro de tecnologia, Universidade Federal de Alagoas, Maceió, 2006.

OLIVEIRA, Maxwell Ferreira de. Metodologia Científica: Um Manual Para A Realização De Pesquisas Em Administração. Universidade Federal De Goiás, 2011. PINHEIRO, Gustavo Focesi. O gerenciamento da construção civil e o desenvolvimento sustentável: um enfoque sobre os profissionais da área de edificações. 2002. 159f. Dissertação (Mestrado em Engenharia Civil) - Faculdade de Engenharia Civil, Universidade Estadual de Campinas, Campinas, 2002.

SOUZA, Adriene Pereira Cobra Costa Bambu na habitação de interesse social no Brasil. Cadernos de Arquitetura e Urbanismo, Belo Horizonte, v. 11, n. 12, p. 217-245, dez. 2004

VILLELA, Dianna Santiago.A sustentabilidade na formação atual do arquiteto e urbanista. 2007. 179f. Dissertação (Mestrado em Arquitetura e Urbanismo) - Escola de Arquitetura. Universidade Federal de Minas Gerais, Belo Horizonte, 2007 